\title{
The modality-specific and -nonspecific components of long-term priming are frequency sensitive
}

\author{
JEFFREY S. BOWERS \\ University of Bristol, Bristol, England
}

\begin{abstract}
Five experiments were carried out to test the claim that the modality-specific and modality-nonspecific components of long-term priming are differentially sensitive to word frequency, with the specific component being less affected. In contrast with this claim, specific and nonspecific priming were similarly reduced for high-frequency words in three lexical decision and two perceptual identification experiments. These findings highlight the important role of frequency in modulating priming as well as provide a basic constraint for future theories of priming. In addition, the roles of task and student population in modulating priming are examined.
\end{abstract}

Long-term priming refers to facilitation in processing a stimulus as a consequence of having encountered the same (or a related) stimulus in an earlier episode. Generally, this facilitation is measured in terms of an improved accuracy or a reduced latency in identifying studied, as compared with nonstudied stimuli, although other dependent measures have been developed as well (see, e.g., Zajonc, 1980). For example, consider the lexical decision task in which participants decide as quickly as possible whether letter strings are words or not (e.g., blap). Priming is obtained when the participants are faster and more accurate in responding "yes" to previously studied words. This priming is called long term because it lasts minutes, hours, or longer (see, e.g., Roediger, Weldon, Stadler, \& Riegler, 1992), in contrast to various sorts of short-term priming phenomena-such as semantic or masked priming - that typically last only a few seconds (Forster \& Davis, 1984; Henderson, Wallis, \& Knight, 1984; but see Joordens \& Becker, 1997).

During the last 15 years, many properties of long-term priming have been identified (see Roediger \& McDermott, 1993, for an extensive review). For present purposes, three findings are particularly relevant. First, priming is highly sensitive to changes in the modality of the study - test items, with priming often reduced by $50 \%$ or more following a modality shift. This modality effect has most frequently been reported with shifts from auditory study (i.e., hearing the word) to visual test (i.e., seeing the word; see, e.g., Jacoby \& Dallas, 1981), but the same results have been obtained following visual study and auditory test (e.g., Jackson \& Morton, 1984). Second, priming is sensitive to frequency manipulations, with greater priming for low- than for high-frequency words,

I thank Ernesto Guiterro and Ernest Tolliver for testing the participants and Heidi Ziemer for her help in organizing the experiments. Correspondence concerning this article should be addressed to J. S. Bowers, Department of Experimental Psychology, University of Bristol, 8 Woodland Rd., Bristol, BS8 1TN, England (e-mail: j.bowers@bris.ac.uk). the so-called frequency attenuation effect (see, e.g., Duchek \& Neely, 1989; Forster \& Davis, 1984). It is important to emphasize that both of these results have been repeatedly observed, employing a number of priming tasks (e.g., Blaxton, 1992; Bowers, 1994; Craik, Moscovitch, \& McDowd, 1994; Jacoby \& Dallas, 1981; Kirsner, Milech, \& Stumpfel, 1986; Roediger et al., 1992 ). Accordingly, theories of priming should accommodate these basic facts.

Third, there is some indication that modality and frequency effects interact. That is, frequency appears to differentially modulate the modality-specific and the modality-nonspecific components of priming, which Kirsner, Milech, and Standen (1983) defined as follows. (1) Specific priming $\left(P_{\mathrm{s}}\right)=$ the performance difference between words repeated in the same modality and words repeated in different modalities. (2) Nonspecific priming $\left(P_{\mathrm{ns}}\right)=$ the performance difference between words repeated in different modalities and nonrepeated words. Thus, overall priming $(P)=$ the performance difference between words repeated in the same modality and nonrepeated words, with $P=P_{\mathrm{ns}}+P_{\mathrm{s}}$. On some reports, nonspecific priming was greatly reduced for high-frequency, as compared with low-frequency words, and specific priming was completely insensitive to the frequency manipulation (Kirsner, Dunn, \& Standen, 1989; Kirsner et al., 1983), whereas on other reports, specific priming was also reduced for high-frequency words but was less affected than nonspecific priming (e.g., Kirsner \& Speelman, 1993). Such contrasts between specific and nonspecific priming, if true, should also strongly constrain theory development.

However, the conclusion that frequency and modality effects interact is based on a set of findings that are less than secure. For example, Kirsner et al. (1983) reported that nonspecific priming was selectively affected by frequency manipulations in a perceptual identification task after collapsing across three experiments (Experiments 4-6). However, when the experiments were considered 
separately, only Experiment 6 showed a pattern of priming somewhat compatible with this conclusion, with reduced frequency effects for specific ( $4 \%$ improvement over baseline), as compared with nonspecific (10\% advantage) priming. In two additional studies using the same task, the authors found specific priming to be insensitive to frequency (Experiment 7), whereas nonspecific priming was reduced for high-frequency, as compared with low-frequency words (Experiment 8 ). However, the authors did not report whether there was a significant interaction between frequency, on the one hand, and specific versus nonspecific priming, on the other, which is needed in order to support their claim. The variability in the first set of three studies and the failure to report an interaction between the latter two studies are undoubtedly due to the fact that only 12 participants were tested per study.

Further evidence taken in support of this frequency by modality interaction was reported by Kirsner et al. (1989), who carried out a meta-analysis on a set of published studies for which (1) word frequency could be determined and (2) a modality manipulation was included. Averaging across these studies, the authors reported that frequency effects were largely restricted to the nonspecific component of priming in a variety of tasks. It should be noted, however, that approximately half of the studies were from the Kirsner et al. (1983) paper, and that there were exceptions to this general conclusion. More recently, Kirsner and Speelman (1993) described a number of unpublished studies that also found specific priming to be sensitive to frequency manipulations (although less so than nonspecific priming), and Kirsner, Dunn, Kinoshita, Standen, and Haslacher (1993) reported that specific priming in Kanji is actually more sensitive than nonspecific priming. The authors attributed this last finding to the particular structure of the Kanji orthography.

Clearly, then, the current evidence is quite mixed. Averaging across the few studies that have been carried out, there is some indication that nonspecific priming is more sensitive to frequency than specific priming (in English), although there is no single study that has reported a significant interaction between these variables. It is even less clear whether specific priming is insensitive to frequency or merely less sensitive.

Given the fundamental role that frequency plays in word identification and the extensive research that has directly assessed the role of word frequency in masked priming phenomena (e.g., Bowers, Vigliocco, \& Haan, 1998; Forster \& Davis, 1984; Segui \& Grainger, 1990), it is surprising that so little research effort has been directed at characterizing the role that frequency plays in modulating specific and nonspecific long-term priming. The present investigation attempts to clarify matters in a series of five experiments by manipulating frequency and study-test modality, using within-subjects designs and including two different measures of priming (perceptual identification and lexical decision).
As a secondary issue, the present investigation also assessed the role of student population on priming. That is, experiments were carried out at two universities, one of which has unusually high entrance requirements and a second with more typical entrance requirements. The question of interest is whether the same pattern of priming is obtained across schools. The role of student population in modulating priming has not been considered previously, but to the extent that frequency affects priming, it is not implausible that different results may also be obtained at different schools - given that students attending schools with different entrance requirements presumably have different reading skills, on average, and read differing amounts. Thus, it is interesting to see whether this factor also plays a role in priming.

\section{EXPERIMENTS 1-4}

In the first four experiments, priming was assessed for the same set of words, and only the subject population and priming task varied across experiments. Accordingly, the studies are described together.

\section{Method}

Participants. Ninety-six students enrolled at a university with unusually high admission requirements and 96 students enrolled in a university with standard admission requirements were tested. Students from each institution participated in return for course credit, and the only requirement for inclusion in the study was that they should be native English speakers. Accordingly, the reading skills of students in the two groups overlapped to some extent, with students at the former university reading more quickly, on average. Evidence for the different verbal skills of these students comes from the verbal SAT scores of the students, which averaged approximately 700 at the school with high requirements and 515 at the school with normal requirements. Forty-eight students participated in each study.

Design and Materials. The critical test materials consisted of a set of 96 words and a corresponding number of pseudowords. Fortyeight of the words were high frequency (mean frequency $=128$, with a range of 53-442 occurrences per million), and 48 were low frequency (mean frequency $=4$, with a range of $0-10$ occurrences per million; Kučera \& Francis, 1967). High- and low-frequency words were similar in terms of number of letters ( $5.7 \mathrm{vs} .5 .6$, respectively) and number of syllables (1.6 vs. 1.9). The pseudowords were also matched in length with the words and were pronounceable. During the study phase, 16 high- and 16 low-frequency words were visually presented in uppercase, 16 high- and 16 low-frequency words were presented auditorily, and the remaining 16 high- and 16 low-frequency words were not presented. In the test phase, the participants completed either the lexical decision or the identification task. In the lexical decision task, the 96 words were randomly intermixed with the set of pseudowords, all of which were presented in lowercase format. In the identification task, only the 96 words were presented, again in lowercase. Thus, in both experiments, items were presented in different cases at study and at test. This is consistent with Kirsner et al.'s (1983) procedure. Three test versions were created for both the identification and the lexical decision tasks, so that each word was included in the within-modality, crossmodality, and baseline conditions equally often, creating fully counterbalanced designs.

Procedure. The experiments were conducted under conditions of incidental encoding: The students were told that they were par- 
Table 1

Percentage (\%) of High- and Low-Frequency Words

Identified in the Perceptual Identification Task

as a Function of the Study-Test Condition and

School Entrance Requirements in Experiments 1-2

\begin{tabular}{|c|c|c|c|c|c|c|c|c|c|c|}
\hline \multirow{3}{*}{$\begin{array}{l}\text { Entrance } \\
\text { Requirement }\end{array}$} & \multicolumn{5}{|c|}{ High-Frequency } & \multicolumn{5}{|c|}{ Low-Frequency } \\
\hline & \multicolumn{2}{|c|}{ Repeat } & \multicolumn{2}{|c|}{$\begin{array}{l}\text { Cross- } \\
\text { Modal } \\
\end{array}$} & \multirow[b]{2}{*}{ Baseline } & \multicolumn{2}{|c|}{ Repeat } & \multicolumn{2}{|c|}{$\begin{array}{l}\text { Cross- } \\
\text { Modal }\end{array}$} & \multirow[b]{2}{*}{ Baselin } \\
\hline & $\%$ & $\overline{\mathrm{Pr}}$ & $\%$ & $\overline{\operatorname{Pr}}$ & & $\%$ & $\mathrm{Pr}$ & $\%$ & $\overline{\mathrm{Pr}}$ & \\
\hline High & 62.0 & 9.8 & 56.3 & 4.1 & 52.2 & 52.0 & 13.4 & 44.9 & 6.3 & 38.6 \\
\hline Standard & 56.0 & 7.9 & 50.4 & 2.3 & 48.1 & 49.1 & 16.6 & 39.1 & 6.6 & 32.5 \\
\hline
\end{tabular}

Note-Pr, priming score.

ticipating in an experiment concerned with word perception, and they were not informed that items were repeated later at test. The items were presented on a Multisync monitor controlled by a 486 IBM PC, using the DMASTER display software developed by Kenneth Forster and Jonathan Forster at the University of Arizona, which synchronizes the timing of the display with the video raster. Standard IBM text font was used. The same computer equipment was used for all the studies, and the same experimenters conducted all the studies. The studies were carried out at the students' home institution - that is, at the schools with high and standard entrance requirements.

Perceptual identification. In a pretest, an attempt was made to determine an exposure duration for each participant that resulted in an identification rate of approximately $50 \%$ for nonstudied words. To this end, the participants were presented with an initial identification task that assessed their ability to identify a set of 25 practice words, all of which were different from the critical set of words. On each trial, the target item was presented for $30 \mathrm{msec}$, immediately preceded and followed for 1 sec by a mask (\#\#\#\#\#\#) composed of a series of pound characters. The participants were asked to name the flashed word and to guess, if necessary. On the basis of their performance, the participants were assigned to the slow $(35 \mathrm{msec})$, medium ( $30 \mathrm{msec})$, or fast $(27 \mathrm{msec})$ version of the experiment.

During the study phase, words were presented every $4 \mathrm{sec}$ in a random order. In order to ensure that the participants were paying attention, they were required to press the left shift key on the keyboard for one-syllable words and the right shift key for words with two or more syllables. These responses were not recorded. Following the encoding task, the students completed the perceptual identification task. The identification task contained 10 practice items followed by the 96 target items, and the students could not distinguish between practice and target items. Both practice and target items were presented for an exposure duration determined in the first part of the experiment, and once again, the items were immediately preceded and followed for $1 \mathrm{sec}$ by the pattern mask. As in the initial identification task, the participants were asked to guess when they were unsure. The experimenter recorded the students' responses by pressing the right shift key for correct and the left shift key for incorrect responses. The words were presented in the same random order to all the participants, so that the experimenter could correctly score the responses.

Lexical decision. The students first completed the study phase, which was identical to the above, followed by the lexical decision task. The lexical decision task included a set of 20 practice items ( 10 words and 10 nonwords) that were different from the 96 critical words and the 96 nonword foils. On each trial, a fixation point $(+)$ was displayed for $500 \mathrm{msec}$ followed by the target, which was displayed in lowercase letters for $500 \mathrm{msec}$. The participants were instructed to press the right shift key of the computer keyboard as quickly as possible if the item was a word and the left shift key if it was a pseudoword. Items were presented in a different random order to each participant.

\section{Results}

The results of the two perceptual identification experiments are presented in Table 1 , and the results of the two lexical decision experiments are presented in Table 2. In addition, the specific, nonspecific, and overall priming in the various conditions in all four experiments are displayed in Table 3. Analyses of variance (ANOVAs) were carried out in each experiment, treating subjects $\left(F_{1}\right)$ and items $\left(F_{2}\right)$ as random variables.

Experiment 1: Perceptual identification performance for participants attending a school with standard entrance requirements. The percentage of words identified in the various conditions was entered into an overall ANOVA. A main effect of priming was obtained $\left[F_{1}(2,90)=26.24, M S_{\mathrm{e}}=141, p<.01 ; F_{2}(2,180)=\right.$ $\left.31.16, M S_{\mathrm{e}}=119, p<.01\right]$, reflecting a higher accuracy rate in identifying words in the repeated $(52.6 \%)$ and crossmodal $(44.8 \%)$ conditions, as compared with the baseline $(40.3 \%)$ condition. In addition, a main effect of frequency was obtained $\left[F_{1}(1,45)=66.16, M S_{\mathrm{e}}=138\right.$, $\left.p<.01 ; F_{2}(1,90)=13.05, M S_{\mathrm{e}}=702, p<.01\right]$, with more high- $(51.5 \%)$ than low- $(40.2 \%)$ frequency words iden-

Table 2

Mean Latencies (RT) and Error Rates (\%E) for Lexical Decisions for High- and Low-Frequency Words as a Function of the Study-Test Condition and School Entrance Requirements in Experiments 3-4

\begin{tabular}{|c|c|c|c|c|c|c|c|c|}
\hline \multirow[b]{4}{*}{ Words } & \multicolumn{8}{|c|}{ Entrance Requirement } \\
\hline & \multicolumn{4}{|c|}{ High } & \multicolumn{4}{|c|}{ Standard } \\
\hline & \multicolumn{2}{|c|}{ RT } & \multicolumn{2}{|c|}{$\% \mathrm{E}$} & \multicolumn{2}{|c|}{$\mathrm{RT}$} & \multicolumn{2}{|c|}{$\% \mathrm{E}$} \\
\hline & $M$ & $\mathrm{Pr}$ & $M$ & $\mathrm{Pr}$ & $M$ & $\operatorname{Pr}$ & $M$ & $\mathrm{Pr}$ \\
\hline \multicolumn{9}{|l|}{ High-frequency } \\
\hline Repeat & 484 & 9 & 3.5 & -0.4 & 578 & 6 & 1.8 & 0.8 \\
\hline Cross-modal & 490 & 3 & 3.0 & 0.1 & 585 & -1 & 2.5 & 0.1 \\
\hline Baseline & 493 & & 3.1 & & 584 & & 2.6 & \\
\hline \multicolumn{9}{|l|}{ Low-frequency } \\
\hline Repeat & 507 & 22 & 5.8 & 5.9 & 616 & 47 & 4.4 & 4.2 \\
\hline Cross-modal & 519 & 10 & 7.3 & 4.4 & 636 & 27 & 6.8 & 1.8 \\
\hline Baseline & 529 & & 11.7 & & 663 & & 8.6 & \\
\hline
\end{tabular}

Note-Pr, priming score. 
Table 3

\begin{tabular}{|c|c|c|c|c|c|c|}
\hline $\begin{array}{r}\text { Modality } \\
\text { for High } \\
\text { School } \\
\text { Le }\end{array}$ & $\begin{array}{l}\text { Specific, } \\
\text { (HF) and } \\
\text { With Hig } \\
\text { in the Pe } \\
\text { ical Decis }\end{array}$ & $\begin{array}{l}\text { Modality-Non } \\
\text { I Low-Freque } \\
\text { h and Stand } \\
\text { reeptual Iden } \\
\text { sion (LD) Tas }\end{array}$ & $\begin{array}{l}\text { ispecific, a } \\
\text { ancy (LF) } \\
\text { ard Entran } \\
\text { atification ( } \\
\text { sks in Expe }\end{array}$ & $\begin{array}{l}\text { nd Ov } \\
\text { Nords } \\
\text { ce Re } \\
\text { (ID) a } \\
\text { rimer }\end{array}$ & $\begin{array}{l}\text { erall Pri } \\
\text { Obtaine } \\
\text { quireme } \\
\text { nd } \\
\text { its } 1-4\end{array}$ & $\begin{array}{l}\text { aing } \\
\text { at } \\
\text { ts }\end{array}$ \\
\hline & & Priming Test & Entrance $\mathrm{R}$ & equire & ment & \\
\hline & ID $/$ & ID/ & $\mathrm{LD} / \mathrm{Hig}$ & & LD/Stand & lard \\
\hline Priming & High $(\%)$ & Standard $(\%)$ & $\mathrm{RT}$ (msec) & $\% \mathrm{E}$ & $\mathrm{RT}$ (msec) & $\% \mathrm{E}$ \\
\hline Specific & & & & & & \\
\hline $\mathrm{HF}$ & 6 & 6 & 6 & -0.5 & 7 & 0.7 \\
\hline $\mathrm{LF}$ & 7 & 10 & 12 & 1.5 & 20 & 2.4 \\
\hline Nonspecifi & & & & & & \\
\hline HF & 4 & 2 & 3 & 0.1 & -1 & 0.1 \\
\hline LF & 6 & 7 & 10 & 4.4 & 27 & 1.8 \\
\hline Overall & & & & & & \\
\hline $\mathrm{HF}$ & 10 & 8 & 9 & -0.4 & 6 & 0.8 \\
\hline LF & 13 & 17 & 22 & 5.9 & 47 & 4.2 \\
\hline
\end{tabular}

tified, and the interaction between priming and frequency was also significant $\left[F_{1}(2,90)=3.72, M S_{\mathrm{e}}=\right.$ $\left.122, p<.05 ; F_{2}(2,180)=3.84, M S_{\mathrm{e}}=119, p<.05\right]$, reflecting the larger overall priming for low- $(11.6 \%)$ than for high- $(5.1 \%)$ frequency words. Repetition priming for the high-frequency words was significant $\left[F_{1}(1,45)=\right.$ $10.90, M S_{\mathrm{e}}=138, p<.01 ; F_{2}(1,90)=5.78, M S_{\mathrm{e}}=275$, $p<.05]$.

In order to determine whether frequency differentially affected the specific and nonspecific components of priming, the specific priming scores (identification rate in the repeated condition minus the identification rate in the crossmodal conditions) and nonspecific priming scores (crossmodal minus baseline identification rates) were entered into an ANOVA. A main effect of frequency was obtained $\left[F_{1}(1,45)=7.38, M S_{\mathrm{e}}=123, p<.01\right.$; $\left.F_{2}(1,90)=7.63, M S_{\mathrm{e}}=120, p<.01\right]$, and no interaction was obtained between frequency and priming $\left[F_{1}(1,45)<\right.$ $\left.1 ; F_{2}(1,90)<1\right]$. These findings indicate that frequency had a similar effect on the modality-specific and modalitynonspecific components of priming, with reductions of $4 \%$ and $5 \%$ for high- and low-frequency words, respectively.

Experiment 2: Perceptual identification performance for students attending a school with high entrance requirements. As above, a main effect of priming was obtained $\left[F_{1}(2,90)=26.02, M S_{\mathrm{e}}=124, p<.01\right.$; $\left.F_{2}(2,180)=25.18, M S_{\mathrm{e}}=128, p<.01\right]$, reflecting the higher accuracy rate in identifying words in the repeated $(57.0 \%)$ and crossmodal $(50.6 \%)$ conditions than in the baseline $(45.4 \%)$ condition. And once again, a main effect of frequency was obtained $\left[F_{1}(1,45)=63.80, M S_{\mathrm{e}}=\right.$ $\left.153, p<.01 ; F_{2}(1,90)=12.06, M S_{\mathrm{e}}=814, p<.01\right]$, with a higher percentage of high- $(56.8 \%)$ than of low$(45.2 \%)$ frequency words identified. However, the interaction between priming and frequency was not significant $\left[F_{1}(2,90)<1 ; F_{2}(2,180)<1\right]$, indicating that a similar amount of priming was obtained for low- $(9.9 \%)$ and high- $(7.0 \%)$ frequency words. Repetition priming for the high-frequency words was again significant $\left[F_{1}(45)=\right.$ $22.28, M S_{\mathrm{e}}=102, p<.01 ; F_{2}(1,90)=7.25, M S_{\mathrm{e}}=316$, $p<.01]$.

In order to determine whether frequency differentially affected the specific and nonspecific components of priming, the specific and nonspecific priming scores were entered into an ANOVA. No effect of frequency was obtained $\left[F_{1}(1,45)=1.22, M S_{\mathrm{e}}=130, p>.25 ; F_{2}(1,90)=1.33\right.$, $\left.M S_{\mathrm{e}}=119, p>.25\right]$, and no interaction was obtained between frequency and priming $\left[F_{1}(1,45)<1 ; F_{2}(1,90)<1\right]$.

Finally, in order to determine whether the size of the repetition priming was different for the two student populations, the identification rates from the two studies were entered into a between-subjects ANOVA. For the low-frequency words, there was no main effect of subject population $\left[F_{1}(1,90)=1.32, M S_{\mathrm{e}}=735, p>.25\right]$, reflecting the similar performance in the two groups. Critically, there was no interaction between repetition priming and student population $\left[F_{1}(2,90)<1\right]$, reflecting the similar priming in the two groups. The same pattern was obtained for the high-frequency words, with no main effect of subject group $\left[F_{1}(1,90)=1.27, M S_{\mathrm{e}}=978, p>\right.$ $.25]$ and no interaction between priming and group $\left[F_{1}(1,90)<1\right]$.

Experiment 3: Lexical decision performance for students attending a school with standard entrance requirements. An ANOVA carried out on the response times (RTs) in the various conditions reveled a main effect of priming $\left[F_{1}(2,90)=11.08, M S_{\mathrm{e}}=1,534, p<.01\right.$; $\left.F_{2}(2,180)=15.88, M S_{\mathrm{e}}=1,201, p<.01\right]$, reflecting the faster responses to words in the repeated $(597 \mathrm{msec})$ and crossmodal $(610 \mathrm{msec})$ conditions than in the baseline $(623 \mathrm{msec})$ condition. The main effect of frequency was also obtained $\left[F_{1}(1,45)=114, M S_{\mathrm{e}}=2,002, p<.01\right.$; $\left.F_{2}(1,90)=54.91, M S_{\mathrm{e}}=4,403, p<.01\right]$, reflecting the shorter latencies to respond to high- $(582 \mathrm{msec})$ than to low- $(639 \mathrm{msec})$ frequency words, and the interaction between priming and frequency was significant $\left[F_{1}(2,90)=\right.$ $8.69, M S_{\mathrm{e}}=1,237, p<.01 ; F_{2}(2,180)=10.68, M S_{\mathrm{e}}=$ $1,201, p<.01]$, reflecting the larger overall priming for low- $(37 \mathrm{msec})$ than for high- $(3 \mathrm{msec})$ frequency words. Indeed, the repetition priming for the high-frequency words was not significant $\left[F_{1}(45)<1 ; F_{2}(1,90)<1\right]$. A similar pattern of results was obtained for the error scores, with significantly fewer errors in the repeated $(3.1 \%)$ and crossmodal $(4.6 \%)$ conditions than in the baseline $(5.6 \%)$ condition $\left[F_{1}(2,90)=6.9, M S_{\mathrm{e}}=21, p<.01\right.$; $\left.F_{2}(2,180)=5.98, M S_{\mathrm{e}}=25, p<.01\right]$. In addition, fewer errors were made to high- $(2.3 \%)$ than to low- $(6.6 \%)$ frequency words $\left[F_{1}(1,45)=62.63, M S_{\mathrm{e}}=21, p<.01\right.$; $\left.F_{2}(1,90)=23.67, M S_{\mathrm{e}}=56, p<.01\right]$. The interaction between priming and frequency approached significance $\left[F_{1}(2,90)=2.1, M S_{\mathrm{e}}=32, p>.1 ; F_{2}(2,180)=2.77\right.$, $\left.M S_{\mathrm{e}}=25, p=.07\right]$.

In order to determine whether frequency differentially affected the specific and nonspecific components of prim- 
ing, the specific and nonspecific priming scores were entered into an ANOVA. For the RTs, a main effect of frequency was obtained $\left[F_{1}(1,45)=16.63, M S_{\mathrm{c}}=1,240\right.$, $\left.p<.01 ; F_{2}(1,90)=19.06, M S_{\mathrm{e}}=1,261, p<.01\right]$, and no interaction was obtained between frequency and priming $\left[F_{1}(1,45)<1 ; F_{2}(1,90)=1.43, M S_{\mathrm{e}}=3,423, p>.2\right]$, indicating that frequency had a similar effect on specific and nonspecific priming, with reductions of 13 and $28 \mathrm{msec}$ for the high- and low-frequency words, respectively. Similarly, for the errors, a main effect of frequency was obtained $\left[F_{1}(1,45)=5.33, M S_{\mathrm{e}}=26, p<.05 ; F_{2}(1,90)=\right.$ $\left.5.57, M S_{\mathrm{e}}=25, p<.05\right]$, and no interaction was obtained between frequency and priming $\left[F_{1}(1,45)<1\right.$; $\left.F_{2}(1,90)<1\right]$.

Experiment 4: Lexical decision performance for students attending a school with high entrance requirements. An overall ANOVA revealed a main effect of priming $\left[F_{1}(2,90)=8.73, M S_{\mathrm{e}}=627, p<.01 ; F_{2}(2,180)=\right.$ $\left.13.01, M S_{\mathrm{e}}=503, p<.01\right]$, reflecting the faster responses to words in the repeated $(496 \mathrm{msec})$ and crossmodal $(504 \mathrm{msec})$ conditions than in the baseline $(511 \mathrm{msec})$ condition. A main effect of frequency was also obtained $\left[F_{1}(1,45)=59.06, M S_{\mathrm{e}}=1,046, p<.01 ; F_{2}(1,90)=\right.$ $36.77, M S_{\mathrm{e}}=1,898, p<.01$ ], reflecting the shorter latencies to respond to high- $(489 \mathrm{msec})$ than to low- $(518 \mathrm{msec})$ frequency words. However, the interaction between priming and frequency only approached significance $\left[F_{1}(2,90)\right.$ $=1.54, M S_{\mathrm{e}}=659, p>.2 ; F_{2}(2,180)=3.56, M S_{\mathrm{e}}=503$, $p<.05]$, reflecting a similar trend for priming for low$(16 \mathrm{msec})$ and high- $(6 \mathrm{msec})$ frequency words. In this case, the repetition priming for the high-frequency words approached significance $\left[F_{1}(1,45)=4.89, M S_{\mathrm{e}}=356\right.$, $\left.p<.05 ; F_{2}(2,90)=2.75, M S_{\mathrm{e}}=542, p>.1\right]$. For the error scores, a main effect of priming was also obtained, with significantly fewer errors in the repeated $(4.7 \%)$ and crossmodal $(5.1 \%)$ conditions than in the baseline $(7.4 \%)$ condition $\left[F_{1}(2,90)=7.5, M S_{\mathrm{e}}=27, p<.01\right.$; $\left.F_{2}(2,180)=6.13, M S_{\mathrm{e}}=34, p<.01\right]$. In addition, fewer errors were made with high- (3.2\%) than with low- $(8.3 \%)$ frequency words $\left[F_{\mathrm{l}}(1,45)=73.7, M S_{\mathrm{e}}=25, p<.01\right.$; $\left.F_{2}(1,90)=18.58, M S_{\mathrm{e}}=100, p<.01\right]$. The interaction between priming and frequency was significant $\left[F_{1}(2,90)\right.$ $=8.04, M S_{\mathrm{e}}=31, p<.01 ; F_{2}(2,180)=7.29, M S_{\mathrm{e}}=34$, $p<.01]$, reflecting the greater priming for low- $(5.2 \%)$ than for high- $(-.3 \%)$ frequency words.

In order to determine whether frequency differentially affected the specific and nonspecific components of priming, the specific and nonspecific priming scores were entered into an ANOVA. For RTs, a main effect of frequency was obtained $\left[F_{1}(1,45)=4.94, M S_{\mathrm{e}}=409, p<.05\right.$; $\left.F_{2}(1,90)=5.81, M S_{\mathrm{e}}=612, p<.05\right]$, and no interaction was obtained between frequency and priming $\left[F_{1}(1,45)<\right.$ $\left.1 ; F_{2}(1,90)<1\right]$, indicating that frequency had a similar effect on the specific and the nonspecific components of priming, with reductions of 6 and $7 \mathrm{msec}$ for the highfrequency words, respectively. Similar results were obtained for the errors, with a main effect of frequency
$\left[F_{1}(1,45)=21.55, M S_{\mathrm{e}}=22, p<.01 ; F_{2}(1,90)=12.99\right.$, $\left.M S_{\mathrm{e}}=36, p<.01\right]$ and no interaction between frequency and priming $\left(F_{1}<1, F_{2}<1\right)$.

Finally, in order to determine whether the size of the repetition priming was different for the two student populations, the RT and error scores from the two lexical decision studies were entered into a between-subjects ANOVA. First, consider the results for the low-frequency words. For the RT data, there was a main effect of population $\left[F_{1}(1,90)=39.87, M S_{\mathrm{e}}=18,345, p<.01\right]$, reflecting the faster overall RTs for students attending the school with higher $(518 \mathrm{msec})$ than with lower $(641 \mathrm{msec})$ entrance requirements. Critically, there was also an interaction between priming and population $\left[F_{1}(1,90)=\right.$ $\left.5.94, M S_{\mathrm{e}}=715, p<.05\right]$, reflecting the reduced priming for students attending the former $(22 \mathrm{msec})$ than for students attending the latter $(47 \mathrm{msec})$ school. The error results also revealed a main effect of population $\left[F_{1}(190)=4.63, M S_{\mathrm{e}}=53.6, p<.05\right]$, reflecting the greater number of errors obtained for students in the former $(8.7 \%)$ than in the latter $(6.5 \%)$ school. The interaction between priming and population did not approach significance $\left[F_{1}(1,90)<1\right]$.

For the high-frequency words, a main effect of population was again obtained for the RT data $\left[F_{1}(1,90)=\right.$ $\left.31.45, M S_{\mathrm{e}}=13,392, p<.01\right]$, reflecting the faster overall RTs for students attending the school with high $(489 \mathrm{msec})$ than for students attending the school with low $(583 \mathrm{msec})$ entrance requirements. However, the interaction between priming and population did not approach significance $\left[F_{1}(1,90)<1\right]$, reflecting the similar priming for students attending the school with normal $(6 \mathrm{msec})$ and high $(9 \mathrm{msec})$ entrance requirements. For error scores, there was no main effect of population $\left[F_{1}(1,90)=1.76\right.$, $\left.M S_{\mathrm{e}}=29.5, p>.15\right]$ and no interaction between priming and population $\left[F_{1}(1,90)<1\right]$.

\section{Discussion}

The main result of the four experiments is relatively clear: Modality-specific and modality-nonspecific priming were similarly affected by frequency, with less priming for high- than for low-frequency words. Although the frequency manipulation often had a small effect on the specific and nonspecific priming, more priming was obtained for low- than for high-frequency words in six out of six conditions for specific priming and in six out of six for nonspecific priming (see Table 3 ). These results contradict the early conclusion of Kirsner and colleagues (Kirsner et al., 1989; Kirsner et al., 1983), who argued that nonspecific priming is selectively sensitive to frequency.

The question of whether specific and nonspecific priming are differentially sensitive to frequency manipulations is more difficult to determine from the present data. There certainly was a trend in this direction, with five out of six conditions showing larger frequency effects for nonspecific priming, consistent with past results. However, the interaction did not approach significance 
in any study, and in most cases (four out of six), the frequency effects for specific and nonspecific priming were within $1 \mathrm{msec}$, or $1 \%$, of each other.

With regard to the secondary issue of interest, these studies suggest that student population is a variable that can affect priming under some conditions. In particular, priming effects were reduced by approximately $50 \%$ for low-frequency words in the lexical decision task for students who attended the school with high, as compared with standard, entrance requirements. One possible interpretation of this finding is that students attending the school with high entrance requirements read more often and thus, on average, have more experience with low-frequency words. This would act to reduce priming effects for these words in the same way that high-frequency words show less priming than low-frequency words within an individual. Note that the hypothesis that student population and word frequency modulate priming in the same manner is consistent with the finding that the perceptual identification task was less sensitive than the lexical decision task to both frequency and population manipulations.

The reason that the perceptual identification task is less sensitive to the frequency and student population manipulations is not entirely clear, but it may be related to one specific procedural difference in the two tasks. That is, in the identification task, the display times for words were adjusted on a person-by-person basis so that the two groups of readers performed similarly. Under conditions in which performance is matched across the two groups, perhaps it is not surprising that similar priming results were obtained. Support for this general argument comes from a recent paper by Ostergaard (1998), who found that the magnitude of priming in a naming task is related to performance in a baseline condition. That is, he obtained more priming when test words were presented in noise than when presented in the clear, with the amount of priming proportional to baseline performance. This general finding fits with the present account, where similar priming was obtained in the two student populations when the baseline performance was matched (the identification task) but not when the baseline performance was different (the lexical decision task).

As a final, related point, the present studies also highlight an important limitation of the lexical decision task. That is, priming in this task was minimal (or eliminated) for high-frequency words in both student populations. These results are consistent with other findings in the literature. For example, Rajaram and Roediger (1993), in a study that compared priming in a number of different tasks, failed to obtain any priming in the lexical decision task and, thus, dropped this task, only to mention the finding in a footnote. The reason is now clear: They included medium-frequency words (average frequency = 29.7 per million), and tested Rice undergraduates who are, on average, fast readers. Similarly, Forster and Davis (1984) failed to obtain long-term priming for high-frequency words in a lexical decision task when participants read words during the study phase. Interestingly, when par- ticipants performed lexical decisions at both study and test, the authors did obtain priming for these items. Accordingly, this limitation may only be observed when different processing tasks are performed at study and at test.

\section{EXPERIMENT 5}

A final experiment was carried out in an attempt to (1) provide stronger statistical support for the conclusion that specific priming is frequency sensitive and (2) provide a stronger test of whether specific and nonspecific priming are differentially sensitive to these frequency manipulations. With regard to the first point, the prior experiments supported the conclusion that specific priming is frequency sensitive by showing an overall effect of frequency, together with a failure to obtain an interaction between frequency and specific/nonspecific priming. A more direct test would be to obtain a frequency effect on the specific component itself. In an attempt to address the above two points, the present experiment included a stronger manipulation of frequency and included a larger sample of students.

\section{Method}

Participants. Eighty-four students from the school with high entrance requirements participated for course credit.

Design and Materials. The critical test materials consisted of set of 96 words and a corresponding number of pseudowords. Forty-eight of the words were high frequency (mean frequency = 524 , with a range of $310-1,815$ occurrences per million), and 48 were low frequency (mean frequency $=1$; Kučera \& Francis, 1967). High- and low-frequency words were closely matched in terms of number of letters ( $5.0 \mathrm{vs}$. 5.0, respectively) and number of syllables (1.4 vs. 1.5). The pseudowords were matched in length with the words and were pronounceable. The design was the same as that in the previous lexical decision experiments.

Procedure. The procedure was the same as that in the lexical decision experiments.

\section{Results}

The mean RTs and error rates in the various conditions are presented in Table 4. An overall ANOVA revealed a main effect of priming $\left[F_{1}(2,162)=25.52, M S_{\mathrm{e}}=602\right.$, $\left.p<.01 ; F_{2}(2,180)=28.45, M S_{\mathrm{e}}=401, p<.01\right]$, reflecting the faster responses to words in the repeated $(515 \mathrm{msec})$ and crossmodal $(522 \mathrm{msec})$ conditions than in the baseline ( $534 \mathrm{msec}$ ) condition. A main effect of frequency was also obtained $\left[F_{1}(1,81)=367, M S_{\mathrm{e}}=1,030\right.$,

\section{Table 4}

Mean Latencies (RTs, in Milliseconds) and Error Rates (\%E) for Lexical Decisions for High- and Low-Frequency Words as a Function of the Study-Test Condition in Experiment 5

\begin{tabular}{|c|c|c|c|c|c|c|c|c|}
\hline \multirow[b]{3}{*}{ Condition } & \multicolumn{4}{|c|}{ High-Frequency } & \multicolumn{4}{|c|}{ Low-Frequency } \\
\hline & \multicolumn{2}{|c|}{ RT } & \multicolumn{2}{|c|}{$\% \mathrm{E}$} & \multicolumn{2}{|c|}{$\mathrm{RT}$} & \multicolumn{2}{|c|}{$\% \mathrm{E}$} \\
\hline & $M$ & $\operatorname{Pr}$ & $M$ & $\operatorname{Pr}$ & $M$ & $\operatorname{Pr}$ & $M$ & $\mathrm{Pr}$ \\
\hline Reneal & 494 & 8 & 3.04 & 0.82 & 536 & 30 & 8.76 & 2.3 \\
\hline Cross-modal & 493 & 9 & 3.48 & 0.38 & 552 & 14 & 11.06 & 6.85 \\
\hline Baseline & 502 & & 3.86 & & 566 & & 17.91 & \\
\hline
\end{tabular}

Note-Pr, priming scores. 
$\left.p<.01 ; F_{2}(1,90)=47.19, M S_{\mathrm{e}}=126, p<.01\right]$, reflecting the shorter latencies to respond to high- $(496 \mathrm{msec})$ than to low- $(551 \mathrm{msec})$ frequency words, and the interaction between priming and frequency was significant $\left[F_{1}(2,162)=11.29, M S_{\mathrm{e}}=512, p<.01 ; F_{2}(2,180)=\right.$ $\left.9.68, M S_{\mathrm{e}}=401, p<.01\right]$, reflecting the larger priming for the low- $(22 \mathrm{msec})$ than for the high- $(9 \mathrm{msec})$ frequency words. Still, repetition priming for the highfrequency words was significant $\left[F_{1}(1,81)=4.74\right.$, $\left.M S_{\mathrm{e}}=561, p<.05 ; F_{2}(1,45)=6.55, M S_{\mathrm{e}}=309, p<.05\right]$. For the error scores, a main effect of priming was obtained, with significantly fewer errors in the repeated $(5.9 \%)$ and crossmodal $(7.3 \%)$ conditions than in the baseline $(10.9 \%)$ condition $\left[F_{1}(2,162)=19.97, M S_{\mathrm{e}}=\right.$ $\left.56, p<.01 ; F_{2}(2,180)=21.5, M S_{\mathrm{e}}=29.6, p<.01\right]$. In addition, fewer errors were made with high $-(3.5 \%)$ than with low- $(12.6 \%)$ frequency words $\left[F_{1}(1,81)=179.6\right.$, $M S_{\mathrm{e}}=58.3, p<.01 ; F_{2}(1.90)=47.19, M S_{\mathrm{e}}=126.9, p<$ $01]$. The interaction between priming and frequency was significant $\left[F_{1}(2,162)=17.7, M S_{\mathrm{e}}=45.5, p<.01 ; F_{2}(2,180)\right.$ $\left.=15.5, M S_{\mathrm{e}}=29.6, p<.01\right]$, reflecting the greater priming for low- $(4.6 \%)$ than for high- $(0.6 \%)$ frequency words.

In order to determine whether frequency differentially affected the specific and nonspecific components of priming, the specific and nonspecific priming scores were entered into an ANOVA. For RTs, a main effect of frequency was obtained $\left[F_{1}(1,81)=21.51, M S_{\mathrm{e}}=475\right.$, $\left.p<.01 ; F_{2}(1,90)=16.52, M S_{\mathrm{e}}=448, p<.01\right]$, and the interaction between frequency and priming approached significance $\left[F_{1}(1,81)=2.46, M S_{\mathrm{e}}=1,648, p>.1\right.$; $\left.F_{2}(1,90)=1.01, M S_{\mathrm{e}}=1,062, p>.3\right]$, reflecting a trend for a greater reduction of specific than of nonspecific priming for high-frequency words, with reductions of 17 and $5 \mathrm{msec}$, respectively. Critically, this $17-\mathrm{msec}$ reduction is significant $\left[F_{1}(81)=10.42, M S_{\mathrm{c}}=1,302, p<.01\right.$; $\left.F_{2}(1,90)=12.0, M S_{\mathrm{e}}=587, p<.01\right]$, providing direct evidence that specific priming is sensitive to frequency manipulations. For errors, there was again a main effect of frequency $\left[F_{1}(1,81)=24.55, M S_{\mathrm{e}}=33.9, p<.01\right.$; $\left.F_{2}(1,90)=29.28, M S_{\mathrm{e}}=49.79, p<.01\right]$, but in this case, there was a trend for a greater reduction of nonspecific than of specific priming $\left[F_{1}(1,81)=3.62, M S_{\mathrm{e}}=123\right.$, $\left.p>.05 ; F_{2}(1,90)=3.38, M S_{\mathrm{e}}=75.8, p>.05\right]$, with reductions of $6.5 \%$ and $1.9 \%$, respectively. Thus, there is some evidence of a speed-accuracy tradeoff, with the specific priming being somewhat more sensitive to frequency manipulations for RTs and the nonspecific priming somewhat more sensitive for errors. Thus, when the RT and the error results are considered together, it appears that the two components of priming are similarly affected by frequency.

\section{Discussion}

Consistent with the first four experiments, specific and nonspecific priming were similarly affected by the frequency manipulation. This final experiment also provided direct statistical support for the claim that specific priming is sensitive to frequency manipulations, which con- trasts with the previous experiments, which relied on a nonsignificant interaction between frequency, on the one hand, and specific/nonspecific priming, on the other, to support this conclusion.

\section{GENERAL DISCUSSION}

The present set of experiments provide clear evidence that specific and nonspecific priming are sensitive to frequency manipulations, contrary to the early claims of Kirsner and colleagues (Kirsner et al., 1989; Kirsner et al., 1983), who suggested that specific priming is insensitive to frequency. The present results are less clear regarding the relative sensitivity of specific and nonspecific priming. In most of the experiments above, there was a small trend for nonspecific priming to be more sensitive to frequency manipulations than was specific priming, although this was not the case in the final experiment, which had the most power. Whatever the ultimate conclusion, the present experiments make it clear that there is not a large difference in the sensitivity of specific and nonspecific priming to frequency, as has been assumed by some later work by Kirsner and colleagues (e.g., Kirsner \& Speelman, 1993).

These results have a number of methodological and theoretical implications. At a methodological level, three main points should be made. First, and most generally, the results highlight the need to consider word frequency when selecting materials, as has been documented by many previous findings as well (e.g., Forster \& Davis, 1984). Indeed, failures to consider this variable have led to a number of mistaken theoretical conclusions (see Bowers, 1999, 2000a, 2000b). Second, the studies show that student population can modulate priming in at least one task - namely, the lexical decision task. Although this variable does not affect priming to the extent that frequency does, priming was reduced by half for lowfrequency words for students who attended the school with high entrance requirements. Accordingly, this variable should be considered when designing experiments. Third, the results indicate that different priming tasks are differentially affected by frequency (and population) manipulations, with the lexical decision task being more sensitive than the perceptual identification task. Most striking, the lexical decision task often did not support significant priming for high-frequency words, and this was the case for both student groups.

In addition, the present results provide a basic empirical constraint for future theory development. Most current theories of priming have not attempted to accommodate frequency effects (e.g., Masson \& Freedman, 1990; Roediger, 1990; Schacter, 1990; Squire, 1987; Tulving \& Schacter, 1990; but see Logan, 1990) and, thus, make no relevant predictions regarding the role of frequency in modulating specific and nonspecific priming. Clearly, these theories should be developed to accommodate these facts. It is worth noting, however, that one standard model of priming does correctly predict fre- 
quency effects for the specific component of priming -.. namely, Morton's logogen model of word recognition (Morton, 1979). On this theory, a preexisting lexical orthographic code (or visual "logogen") is strengthened each time a word is studied, and this leads to a facilitation in processing the word when it is later presented at test, resulting in priming. A critical assumption of this approach is that the lexical orthographic representations are themselves coded according to frequency. Thus, according to additive factors logic (Sternberg, 1969), modalityspecific priming and frequency should interact, as was observed. Although the present findings do not uniquely support this approach, there is now a growing body of evidence in support of this general approach (Bowers, 1996, 1999; Bowers \& Michita, 1998).

A similar account might explain the frequency-sensitive nature of the nonspecific priming; that is, preexisting lexical-phonological representations (auditory "logogens") coded for frequency may mediate this priming. Some support for the conclusion that lexical-phonological codes mediate crossmodal priming was obtained by Ziemer and Bowers (2000). Consistent with the standard finding, twice as much within-modal $(18 \mathrm{msec})$ as crossmodal $(9 \mathrm{msec})$ priming was obtained in a lexical decision task when the distractor nonword foils were pseudowords (e.g., blap). The new finding was that the inclusion of pseudohomophone nonword foils (e.g., brane, which sounds like brain) eliminated crossmodal priming $(-2 \mathrm{msec})$ but left within-modal priming ( $16 \mathrm{msec})$ unchanged. We argued that the inclusion of pseudohomophones foils discouraged participants from using phonology as a basis for making lexical decisions, and given that this manipulation also eliminated crossmodal priming, it suggests that phonological codes supported crossmodal priming when pseudoword foils were included (which is the standard type of nonword foil used in lexical decision tasks, including the experiments described here). In addition, the claim that lexical-phonological codes support nonspecific priming provides a plausible account for the present finding that specific and nonspecific priming are similarly affected by frequency.

In sum, both the specific and the nonspecific components of priming are sensitive to frequency manipulations, with more priming for low-frequency words. I would suggest that these findings lend support to the view according to which specific and nonspecific priming is mediated, in large part, by lexical-orthographic and lexicalphonological codes, respectively. But whatever the proper interpretation, these findings provide an important constraint for future theory development.

\section{REFERENCES}

BLAXTON, T. A. (1992). Dissociations among memory measures in memory-impaired subjects: Evidence for a processing account of memory. Memory \& Cognition, 20, 549-562.

BOWERS, J. S. (1994). Does implicit memory extend to legal and illegal nonwords? Journal of Experimental Psychology: Learning, Memory \& Cognition, 20, 534-549.
BOWERS, J. S. (1996). Different perceptual codes support word and pseudoword priming: Was Morton right all along? Journal of Experimental Psychology: Learning, Memory, \& Cognition, 22, 1336-1353.

Bowers, J. S. (1999). Priming is not all bias: Commentary on Ratcliff and McKoon (1997). Psychological Review, 106, 582-596.

BOWERS, J. S. (2000a). In defense of abstractionist theories of repetition priming and word identification. Psychonomic Bulletin \& Review, 7, 83-99.

Bowers, J. S. (2000b). Perceptual priming is obtained in a semantic classification task: Comment of E. Vriezen, M. Moscovitch, and S. A. Bellos (1995). Manuscript submitted for publication.

BOWERS, J. S., \& MiChITA, Y. (1998). An investigation into the structure and acquisition of orthographic knowledge: Evidence from crossscript Kanji-Hiragana priming. Psychonomic Bulletin \& Review, 5, 259-264.

Bowers, J. S., Vigliocco, G., \& HaAN, R. (1998). Orthographic, phonological, and articulatory contributions to masked letter and word priming. Journal of Experimental Psychology: Human Perception \& Performance, 24, 1705-1719.

Craik, F. I. M., Moscovitch, M., \& McDowd, J. M. (1994). Contributions of surface and conceptual information to performance on implicit and explicit memory tests. Journal of Experimental Psychology: Learning, Memory, \& Cognition, 20, 864-875.

DUCHEK, J. M., \& NEELY, J. H. (1989). A dissociative word-frequency $\times$ levels-of-processing interaction in episodic recognition and lexical decision tasks. Memory \& Cognition, 17, 148-162.

FORSTER, K. I., \& DAVIS, C. (1984). Repetition priming and frequency attenuation in lexical access. Journal of Experimental Psychology: Learning, Memory, \& Cognition, 10, 680-698

Henderson, L., Wallis, J., \& Knight, D. (1984). Morphemic structure and lexical access. In H. Bouma \& D. G. Bouwhuis (Eds.), Attention and performance $X$ : Control of language processes (pp. 211226). Hillsdale, NJ: Erlbaum.

JACKSON, A., \& MORTON, J. (1984). Facilitation of auditory word recognition. Memory \& Cognition, 12, 568-574.

JACOBY, L. L., \& DALLAS, M. (1981). On the relationship between autobiographical memory and perceptual learning. Journal of Experimental Psychology: General, 110, 306-340.

JOORDENS, S., \& BECKER. S. (1997). The long and short of semantic priming effects in lexical decision. Journal of Experimental Psychology: Learning, Memory, \& Cognition, 23, 1083-1105.

Kirsner, K., Dunn, J. C., Kinoshita, S., Standen, P., \& HasLACHER. T. (1993). Script and representation: Many processes; one principle. In J.-T. Huang \& O. J. L. Tzeng (Eds.), Proceedings of the Sixth International Symposium on Cognitive Aspects of the Chinese Language (pp. 127-143). Taipei: National Taiwan University.

KirSner, K., DunN, J. C., \& Standen, P. (1989). Domain-specific resources in word recognition. In S. Lewandowsky, J. C. Dunn, \& K. Kirsner (Eds.), Implicit memory: Theoretical issues (pp. 99-122). Hillsdale, NJ: Erlbaum.

Kirsner, K., Milech, D., \& Standen, P. (1983). Common and modalityspecific processes in the mental lexicon. Memory \& Cognition, 11, $621-630$

KirSner, K., Milech, D., \& Stumpfel, V. (1986). Word and picture identification: Is representational parsimony possible? Memory \& Cognition, 14, 398-408

KirSNER, K., \& Speelman, C. P. (1993). Is lexical processing just an ACT? In A. Collins, M. Conway, S. Gathercole, \& P. Morris (Eds.), Theories of memory (pp. 303-326). Hillsdale, NJ: Erlbaum.

KuČERA, J., \& FrANCIS, W. N. (1967). Computational analysis of present day American English. Providence, RI: Brown University Press.

LOGAN, G. D. (1990). Repetition priming and automaticity: Common underlying mechanisms? Cognitive Psychology, 22, 1-35.

MASSON, M. E. J., \& FreEdMAN, L. (1990). Fluent identification of repeated words. Journal of Experimental Psychology: Learning, Memory. \& Cognition, 12, 479-488.

MORTON, J. (1979). Facilitating in word recognition: Experiments causing change in the logogen model. In P. A. Kolers, M. E. Wrolstad, \& H. Bouma (Eds.), Processing models of visual language (pp. 259268). New York: Plenum. 
OstergaARD, A. L. (1998). The effects on priming of word frequency, number of repetitions, and delay depend on the magnitude of priming. Memory \& Cognition, 26, 40-60.

Rajaram, S., \& RoEDiger, H. L., III (1993). Direct comparison of four implicit memory tests. Journal of Experimental Psychology: Learning, Memory, \& Cognition, 19, 765-776.

RoEDIGER, H. L., III (1990). Implicit memory: Retention without remembering. American Psychologist, 45, 1043-1056.

ROEDIGER, H. L., III, \& MCDERMOTT, K. B. (1993). Implicit memory in normal human subjects. In F. Boller \& J. Grafman (Eds.), Handbook of neuropsychology (Vol. 8, pp. 63-131). Amsterdam: Elsevier.

Roediger, H. L., III, Weldon, M. S., Stadler, M. A., \& Riegler, H. G. (1992). Direct comparison of word stems and word fragments in implicit and explicit retention tests. Journal of Experimental Psychology: Learning, Memory, \& Cognition, 18, 1251-1269.

SCHACTER, D. L. (1990). Perceptual representation system and implicit memory: Toward a resolution of the multiple memory debate. In A. Diamond (Ed.), Development and neural basis of higher cognitive function (Annals of the New York Academy of Sciences, Vol. 608, pp. 543-571). New York: New York Academy of Sciences.
Segui, J., \& Grainger, J. (1990). Priming word recognition with orthographic neighbors: Effects of relative prime-target frequency. Journal of Experimental Psychology: Human Perception \& Performance, 16, $65-76$.

SQuire, L. R. (1987). Memory and brain. New York: Oxford University Press.

SternberG, S. (1969). The discovery of processing stages: Extensions of Donder's method. In W. G. Koster (Ed.), Attention and performance II (pp. 58-87). Amsterdam: North-Holland.

Tulving, E., \& Schacter, D. L. (1990). Priming and human memory systems. Science, 247, 301-306.

ZAJONC, R. B. (1980). Feeling and thinking: Preferences need no inferences. American Psychologist, 35, 51-175.

Ziemer, H., \& Bowers, J. S. (2000). Phonological and orthographic contributions to long-term priming in the lexical decision task. Manuscript submitted for publication

(Manuscript received September 17, 1998; revision accepted for publication March 14, 1999.) 